\title{
Modeling the Performance of Amorphous Silicon in Different Typologies of Curved Building-integrated Photovoltaic Conditions
}

\author{
M. Esmaeili Shayan, G. Najafi*, B. Ghobadian, S. Gorjian \\ Department of Biosystems Engineering, Tarbiat Modares University (TMU), Tehran, Iran
}

\section{$P A P E R \quad I N F O$}

Paper history:

Received 01 January 2022

Accepted in revised form 13 February 2022

\section{Keywords:}

Photovoltaic cells

Renewable energy

Amorphous photovoltaic

Crystal photovoltaic

MATLAB

\section{$A B S T R A C A$}

Photovoltaic cells are a significant renewable energy source due to their cheap cost and renewability. In both warm sunny and colder and cloudier conditions, a-Si modules outperform c-Si modules on a normalized energy basis. This study investigated $1 \mathrm{~m}^{2}$ of amorphous photovoltaic silicon on curved surfaces. The Taguchi and response surface methods were utilized to expand the model in real terms. Results demonstrated the technology gap in the use of silicon crystal photovoltaics is eliminated. The maximum power in the Taguchi method test is $59.87 \mathrm{~W}$, while the minimum power is $57.84 \mathrm{~W}$ when the system is deployed on a flat surface, and the maximum power in the RSM Test is $61.14 \mathrm{~W}$ when the system is deployed on a hemispherical surface, and the minimum power is $56.6 \mathrm{~W}$ when the system is deployed on a flat surface. The minimal performance was $7.1 \%$ on a level surface. The flat surface produced 810 $\mathrm{kWh}$, the cylindrical surface $960 \mathrm{kWh}$, and the hemisphere $1000 \mathrm{kWh}$. The NPV at Flat surface is $\$ 697.52$, with a $34.81 \%$, IRR and an 8.58-year capital return period. Hemisphere and cylindrical surfaces both get $\$ 955.18$. The investment yield was $39.29 \%$ for cylindrical constructions and $40.47 \%$ for hemispheres. On the flat surface, doubling fixed investment improved IRR by $21.3 \%$. The cylindrical system increased by $25.59 \%$ and the hemisphere by $24.58 \%$. The developed simulation model is empirically evaluated using a MATLAB computer tool; the key findings from the validation procedure are reported in this study.

doi: $10.5829 /$ ijee.2022.13.01.10

\begin{tabular}{|c|c|c|c|}
\hline \multicolumn{2}{|c|}{ Symbols } & \multicolumn{2}{|c|}{ Greek Symbols } \\
\hline$A$ & Area $\left(\mathrm{m}^{2}\right)$ & $\gamma$ & Wind Speed $\left(\mathrm{m} \cdot \mathrm{s}^{-1}\right)$ \\
\hline$C_{c f}$ & Net Annual Cash Flow (\$) & $\eta$ & Efficiency $(\%)$ \\
\hline$C F_{i}$ & Cash Flow in the Time Period $(\$)$ & \multicolumn{2}{|c|}{ Subscript } \\
\hline$C_{i n v}$ & Initial Investment (\$) & $\mathrm{mmp}$ & Maximum Power Point \\
\hline$F$ & Flexibility (Degree) & $\mathrm{sc}$ & Short Circuit Current \\
\hline$F F$ & Fill Factor (\%) & $\mathrm{oc}$ & Open Circuit Voltage \\
\hline$F i T$ & Feed in Tariff $\left(\$ . \mathrm{kWh}^{-1}\right)$ & \multicolumn{2}{|c|}{ Abbreviations } \\
\hline$G$ & Irradiance $\left(\mathrm{W} \cdot \mathrm{m}^{-2}\right)$ & $\mathrm{a}-\mathrm{Si}$ & Amorphous Silicon \\
\hline$I$ & Current (A) & $\mathrm{BCR}$ & Benefit Cost Ratio \\
\hline $\operatorname{IRR}$ & Internal Rate of Return (\%) & BIPV & Built Integrated Photovoltaic \\
\hline$N C F_{i}$ & Net Cash Flow for Period i (\$) & BOS & Balance of System \\
\hline$N P V$ & Net Present Value (\$) & $\mathrm{c}-\mathrm{Si}$ & Crystalline Silicon \\
\hline$P$ & Power (W) & FPVS & Flexible Photovoltaic Systems \\
\hline$r$ & Discount Rate (\%) & GHG & Greenhouse Gases \\
\hline$S_{t}$ & Array Layer $\left(\mathrm{m}^{2}\right)$ & PBP & Payback Period \\
\hline
\end{tabular}

*Corresponding Author Email: g.najafi@modares.ac.ir (G. Najafi)

Please cite this article as: M. Esmaeili Shayan, G. Najafi, B. Ghobadian, S. Gorjian, 2022. Modeling the Performance of Amorphous Silicon in Different Typologies of Curved Building-integrated Photovoltaic Conditions, Iranian (Iranica) Journal of Energy and Environment, 13(1), pp.8797. Doi: $10.5829 /$ ijee.2022.13.01.10 


\begin{tabular}{llll}
$S / N$ & Signal to Noise $(\mathrm{dB})$ & PV & Photovoltaic \\
$T$ & Temperature $\left({ }^{\circ} \mathrm{C}\right)$ & RSM & Response Surface Methodology \\
$t$ & Time $(\mathrm{s})$ & SNR & Signal to Noise Ratio \\
$V$ & Voltage $(\mathrm{V})$ & STC & Standard Test Conditions \\
\hline
\end{tabular}

\section{INTRODUCTION}

Photovoltaic cells are a popular renewable energy source due to their cheap material costs, environmental friendliness, and recyclability. When installing solar cell modules, it is necessary to take into account environmental conditions such as ambient humidity, air dust, wind speed, and ambient temperature. Therefore, in order for photovoltaic cells to perform efficiently and widely, it is essential to build solar panels that are corrosion-resistant and long-lasting. In comparison to monocrystalline and polycrystalline silicon, amorphous silicon (a-Si:H) thin-film photovoltaic cells have a greater absorption coefficient and can absorb enough sunlight to generate high-efficiency solar cells with a $500 \mathrm{~nm}$ thickness [1]. In recent years, the development of solar energy systems has been powered by the fast rise of photovoltaic (PV) technology. Indeed, worldwide installed photovoltaic capacity surpassed $300 \mathrm{GW}$ in 2016, equating to an annual energy production of 365TWh. PV technology is being employed globally: in 2016, 24 nations surpassed the 1-GW power level, six countries exceeded the $10-\mathrm{GW}$ mark, four countries exceeded the 40-GW mark (Japan 42.8 GW, Germany 41.2 GW, USA $40.3 \mathrm{GW}$ ), and China alone topped 78 GW [2]. Utility-scale applications will account for about $70 \%$ of annual PV additions by 2022, up from 55\% in 2020. Although China's significant FITs for commercial and industrial PV projects increased the ratio of distributed projects from $25 \%$ in 2016 to nearly $45 \%$ in 2018, this trend reversed in 2019 [3]. In the last decades, photovoltaic (PV) technology has been drawing enormous attention worldwide. In the future, solar energy consumption is expected to increase due to further reductions in prices in solar cell technology $[4,5]$. Aside from the non-linear nature and environmental dependability of PV systems, the conversion of energy by PV panels is undesirable [6]. It is a positive step towards obtaining energy from light through the advancement of science. Thanks to further cost reductions and continuous policy support from 120 governments globally, PV capacity additions are forecast to expand to $162 \mathrm{GW}$ in 2022 [7, 8]. Despite the ongoing COVID-19 pandemic, the overall investments in solar energy increased by $12 \%$ to USD 148.6 billion (EUR 125 billion). In 2020, over $135 \mathrm{GW}$ of new solar photovoltaic electricity generation capacity was installed increasing the total cumulative installed capacity to over $770 \mathrm{GW}$ [2]. The quality of electricity and the various sources of supply are now seen as the core solutions of policymakers around the world. Fossil fuels fall from almost four-fifths of total energy supply today to slightly over one-fifth [9]. Some of the most challenging environmental problems are the production and usage of oil resources and greenhouse gases. Every year, non-renewable energy releases a megatonne of greenhouse gases (GHG) into the atmosphere [10, 11]. In South Asia, the concept of using skin-based solar systems is on the increase. Building integrated photovoltaics (BIPV) is increasingly used as a primary or secondary energy source in buildings. Unique criteria for the proper efficiency of the BIPV cells need to be regarded. BIPV is one of the most promising contributors to net-zero energy buildings, while also increasing the aesthetic value of the built environment and Thermal and sound insulation properties [12]. The electrical power from the solar cells is increased by reducing the operating temperature, Like all other semiconductor devices, solar cells are sensitive to temperature. Increases in temperature reduce the bandgap of a semiconductor which leads to the decrease of the module efficiency and output power [13, 14]. Using natural or forced ventilation systems is one of the most effective ways to lower the solar cell temperature and reduce efficiency. In addition, the solar system designer can position the solar cell in the direction of the wind at the correct position $[15,16]$. Iran's energy intensity index is up by a factor of 3 . Developing countries can be expected to find themselves in a similar position. For developed countries, this index is about 0.3 [17]. An increasing human population and the need for energy usage, limitations and inability to react to refined petroleum products have increased the desire to use renewable energy, especially solar energy. Regardless of this, electricity demand per household has increased dramatically over 2007-2018 [18]. It is expected that this growth will occur until 2030 and that the slope will reach 60 percent [19]. In the supply of renewable energy and considered Iran's capacity, solar energy is environmentally sustainable, leading to non- $\mathrm{CO}_{2}$ generation; it also contributes to natural resource sustainability, land recovery, reduced power transmission lines, increased regional energy control, improved speed and cost-effectiveness of electricity transmission into rural areas [20]. Iran's Central Bank has reported that this sector's inflation rate was 10 percent a year based on the average inflation rate between 2011 and 2016 [21]. Research surveys have estimated that Tehran's sunny days and hours are about 313 days and 1742 hours a year, respectively. The increase from the southeast to the northwest of Iran is reduced, whereas it usually increases from the west to the east [22]. The irradiance map and statistical irradiance simulations show that irradiance 
level in clear air is theoretically high in Iran, including Yazd, Kerman, Tabas, Birjand, Iranshahr, Chabahar, Shiraz, Bam, Bushehr, and desert areas. However, building construction does not usually permit traditional solar systems with rigid modules [23]. The flexible solar cells can generate voltages of more than $50 \mathrm{~V}$. These circuits will contain appliances voltage requiring higher setup power in normal mode [24, 25]. Major market trends are described as the inverter, module size, main power, and deployment and Balance of System (BOS) cost decline. With a cumulative annual growth rate of 200th Compound (CAGR), the cost of modules is forecast to decline from 260 cents/Wp in 2009 to 30 cents/Wp in 2018 [26]. The building's shape directly affects its energy use. Modern architecture regularly uses curved forms. They have a significant impact on the building's solar and energy performance, and may improve the internal environment. The curved shape is also used to silos, biogas tanks, greenhouses and structures. The Taguchi factorial experiment and response surface methods are used to improve the precision of the test and reduce the expense of testing and speed up the experiment [27]. Conventional solar panels involve the construction of glass panels that are usually not quite consistent with cylindrical geometric shapes [28]. One of the solutions to these problems is the development and production of solar systems focused on flexible panels that, in addition to supporting the architecture of the desired structures and sustaining the previous capabilities, are economical and provide the energy needs of the electrical equipment for these structures [29]. Rural electrification in Iran was started by using photovoltaic in 2006, first in Qazvin province and then in Gilan, Zanjan, Bushehr, Yazd and Kurdistan provinces [30, 31]. Hydrocarbons dominate Iran's energy mix. Traditional thermal power plants run on natural gas and petroleum derivatives such gasoline and fuel oil. The remaining $2 \%$ comes from hydropower, nuclear, biofuels, and other renewables [32]. Solar power plants have the least capacity of the three grid-connected power plants (wind, biogas, and solar) mounted. Wind provides the majority of renewable energy capacity [29,30].

This property should enable a fair trade-off between the thermal and electrical performance of amorphous photovoltaics in a warm environment. This requires a trade-off between increased heat losses in the winter and lower PV cell temperatures in the summer. Consequently, we think that our research will contribute to the growing body of information about the performance of unglazed, uninsulated Amorphous Photovoltaic plants. This article focuses on the development, modeling, and early experimental validation of a flexible micro photovoltaic power plant with the goal of advancing the state of the art of amorphous photovoltaic silicon systems. The system is explained in full from a hardware standpoint, including both the sustainable and electrical aspects. Additionally, the software used to monitor and manage the plant is discussed. LabVIEW and MATLAB were used to simulate the system, and the simulation findings were compared to experimental data obtained over a 27-day period.

\section{MATERIALS AND METHOD}

\section{Technical analysis}

The current and voltage data collection was obtained by implementing the flat, cylindrical, and spherical surfaces. Flexible layers with suitable depth and durability can cover any design and introduce more incredible energy with selected columns. The structural part of the buildings was created in SketchUp, and the temperature analysis was performed in ANSYS workbench software. The components involved in the solar energy system were modeled in flat, cylindrical, and hemispherical shapes and studied under actual conditions. Data from irradiance, temperature, humidity, wind speed were recorded every 30 minutes through the data logger and sent to LabVIEW software via USB-4711A device. A power meter measures and records the voltage, current, and output power of the systems. The Solar power conversion model based on flexible panels, as shown in Figure 1 includes: geometric arrangement on cylindrical, hemispheric and flat surfaces, flexible solar cell, battery block, irradiance meter, temperature sensor, humidity sensor, anemometer, voltage monitor, power amplifier, planning circuits, battery plugs and fuses, analog-digital converter. The intensity of solar radiation was measured with Multimetrix SPM72 Solar Meter with a maximum error of $\pm 5 \%$ (in the range of $0-1500 \mathrm{~W} / \mathrm{m}^{2}$ and $\pm 0.5^{\circ} \mathrm{C}$ accuracy (in the range of -10 to $110 \mathrm{C}$ ), respectively. Moreover, the Ambient temperature and surface temperature of solar cells were measured using 16 complete circuits of $\operatorname{lm} 35$ sensor connected to USB4711A with $0.1{ }^{\circ} \mathrm{C}$ accuracy and an Extech AN200 Wind sensor with $\pm 5 \%$ accuracy in the wind speed range of 0.4 to $30 \mathrm{~m} / \mathrm{s}$.

Table 1 summarized the flexible solar devices were used in agreement with the standards set out. Amorphous silicon (a-Si) element JNsolar3W-12v with three deposition junction points in a stainless polymer sheet and a lock diode is used to resist the leakage of the battery current to the solar module panel [35].

The most efficient matching layer provided by choice of $1 \mathrm{~m}^{2}$ solar panels could be $9744 \mathrm{~cm}^{2}$. After removing the edges of the flexible solar panel, the photovoltaic section will be equal to $6996 \mathrm{~cm}^{2}$. To cover the cylindrical and hemispherical surfaces with a specified area, 16 flexible solar elements, a cylindrical and hemispherical structure with a particular area is required. A cylinder with a height of $84 \mathrm{~cm}$ and a radius of $18.5 \mathrm{~cm}$, as well as a hemisphere with a radius of $39.38 \mathrm{~cm}$, were designed and built for this purpose. Stress and strain analysis assisted in determining the space between the parts that 


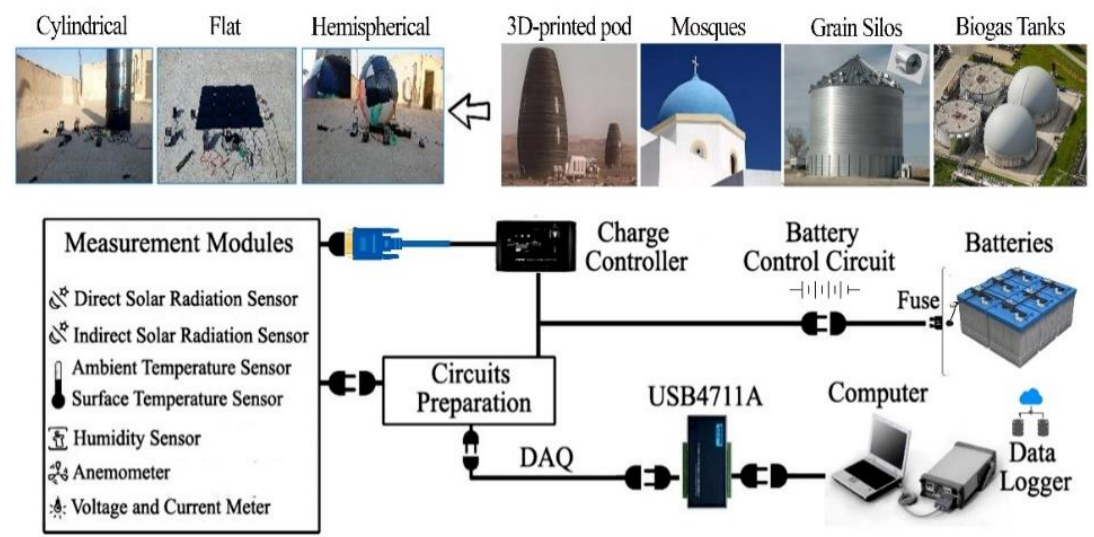

Figure 1. Model of flexible photovoltaic conversion system

Table 1. Specification of flexible solar module Jnsolar3w-12v [36]

\begin{tabular}{lcc}
\hline Characteristic & Unit & Value \\
\hline Power & $\mathrm{W}$ & 3.5 \\
Short-circuit current & $\mathrm{A}$ & 0.3 \\
Absolute point voltage & $\mathrm{V}$ & 12 \\
Open circuit voltage & $\mathrm{V}$ & 14 \\
Dimensions & $\mathrm{mm}$ & $(290 \times 210 \times 5)$ \\
\hline
\end{tabular}

would avoid damage. The structural models were created in SketchUp and the thermal stress analysis in ANSYS Workbench showed a maximum strain of $0.041 \mathrm{~mm}$ in the radius direction. The strain was negligible, but to avoid rupturing the flexible parts, the contact distance was set at $2 \mathrm{~mm}$. The maximum strain is $0.043 \mathrm{~mm}$ in the upper hemisphere. Therefore, a $2 \mathrm{~mm}$ contact distance was considered. The Microcontroller sends 16 temperature sensors per 50 milliseconds through a serial link and, until obtained by LabVIEW, shows them and stores them in an excel file per half-hour in a period. Fill factor (FF) is a parameter that, in conjunction with $\mathrm{V}_{\mathrm{oc}}$ and $\mathrm{I}_{\mathrm{sc}}$, determines the maximum power from a solar cell. The FF is defined as the ratio of the maximum power from the solar cell to the product of $\mathrm{V}_{\mathrm{oc}}$ and $\mathrm{I}_{\mathrm{sc}}$. The match principle is quantitatively similar to the current-voltage supply series, and the higher the amount, the greater the photovoltaic system's output. The fill factor is calculated on the surface according to Equation (1) $[37,38]$. The efficiency of a photovoltaic system is also one of the most critical external measurement items. Efficiency $(\eta)$ is defined by Equation (2) [39].

$$
\begin{aligned}
& \mathrm{FF}=\frac{V_{M P P} \times I_{M P P}}{V_{o c} \times I_{s c}} \\
& \eta=\frac{P / s_{t}}{G}
\end{aligned}
$$

where $G$ equals the irradiance $\left(\mathrm{W} / \mathrm{m}^{2}\right), \mathrm{S}_{\mathrm{t}}$ equals the array layer $\left(\mathrm{m}^{2}\right)$, and $\mathrm{P}$ equals the device power at the target point $(\mathrm{W})$. Use that indexing relationship to measure the output power in shadow mode, temperature shifts, dust fall, light reflection and solar activity on the solar array. Excel 2019 and Design Expert 7 and Minitab 18 were included. In the end, the optimal power system was validated using the Taguchi and Response Surface Methodology (RSM).

\section{Taguchi's and RSM}

Factorial design is used for a variety of tests. Experiments are based on different factors and levels. Taguchi can find the optimal point of operation of variables using a factorial design. Two variables, signal-to-noise $(\mathrm{S} / \mathrm{N})$ and ratio $(\eta, d B)$, can determine the quality of a test designed in Taguchi. A signal-to-noise ratio is a measure of robustness, which can be used to identify the control factor settings that minimize the effect of noise on the response. The signal-to-noise $(\mathrm{S} / \mathrm{N})$ ratio is calculated for each factor level combination. The formula for the nominal-is-best $\mathrm{S} / \mathrm{N}$ ratio using base $10 \log$ is present in the Equation (3) and the larger-is-better $\mathrm{S} / \mathrm{N}$ ratio is shown in Equation (4) [40].

$$
\begin{aligned}
& \mathrm{S} / N=10 \log \left(\frac{\bar{y}^{2}}{s_{y}^{2}}\right) \\
& \mathrm{S} / N=-10 \log \left(\frac{1}{n} \sum_{i=1}^{n} \frac{1}{y^{2}}\right)
\end{aligned}
$$

whereas $n$ is the number of tests of the same level also with the goal of preserving the same $\mathrm{S} / \mathrm{N}$ ratio at all times. The function level corresponding to the absolute average $\mathrm{S} / \mathrm{N}$ ratio is considered the optimum level function. The expected value of the $\mathrm{S} / \mathrm{N}$ ratio $\left(\eta_{\mathrm{opt}}\right)$ at the optimum parameter stage evaluated by Equation (5) is as follows [40]:

$$
\eta_{\text {opt }}=\bar{n}+\sum_{i=1}^{k}\left(n_{m i}-\bar{n}\right)
$$

If $\bar{n}$ is the mean $\mathrm{S} / \mathrm{N}$ ratio of all experimental conditions, 
$\mathrm{k}$ is the number of critical parameters, and $n_{m i}$ is the mean $\mathrm{S} / \mathrm{N}$ ratio of the $\mathrm{i}^{\text {th }}$ control factor corresponding to the optimal process point.

The test phase is divided into three parts: flat, cylindrical and spherical surfaces. Flexible solar panels are connected in series and off-grid from the mains with battery backup. Climatic data for the 27-day test was collected from the Meteorological Station and direct measurement instruments linked to the LabVIEW program. Table 2 shows the test factors and levels in the Taguchi and RSM designs. For this test, 4 variables were chosen: irradiance power at three levels, temperature, wind speed, and flexibility at 3 levels. The irradiance variable is rated from sunrise to sunset from $200 \mathrm{~W} / \mathrm{m}^{2}$ to $1100 \mathrm{~W} / \mathrm{m}^{2}$. The Taguchi test design and RSM method were analyzed based on maximum power generation capacity. Modeling in this test is evaluated based on the criterion "more power is better".

The relation between input and output values can be defined with $\mathrm{x}$ and $\mathrm{y}$ in energy systems design. A model can then be found in literature [40], where $\varepsilon$ characterizes the noise or error reported in y output. When we indicate the output results as:

$$
\begin{aligned}
& y=f\left(x_{1} \cdot x_{2}, \ldots x_{n}\right)+\varepsilon \\
& E(y)=\left(x_{1} \cdot x_{2} \ldots . x_{n}\right)=y
\end{aligned}
$$

The Box-Behnken model design can include flat, cylindrical, and hemispheric surfaces. The model can be designed as follows in a flexible solar system:

$$
\hat{y}=f\left(x_{1} \cdot x_{2} \ldots . x_{n}\right)
$$

\section{Economic analysis}

By analyzing the model's components, engineering economics will decide the rejection or acceptance of a project. COMFAR software has been used in this research, with the complexity of the system's economic variables and technological variables. The parameters used in the economic efficiency analysis for engineering economics are:

\section{Net present value (NPV)}

Considering the economic time adjustment, this criterion creates an equilibrium between investment payments and income generated by investment implementation. This interest is referred to as "minimum attractive interest" or "capital cost". The present value as a set of future cash fund flows is calculated by the Equation (9):

$$
N P V=N C F_{0}+\frac{N C F_{1}}{(1+r)}+\frac{N C F_{2}}{(1+r)^{2}}+\frac{N C F_{i}}{(1+r)^{i}}
$$

$\mathrm{NCF}$ is equal to the net cash funds where its NPV is the net present value, $r$ is the discount and $i$ is proportional to the financial period. NPV may be a negative number (not selecting any project) or a positive number (project selection). If NPV is equal to zero, then the designer will be indifferent to choosing whether to select a project or not.

\section{Benefit cost ratio}

A benefit cost ratio (BCR) is a ratio used in a cost-benefit analysis to summarize the overall relationship between the relative costs and benefits of a proposed project. BCR can be expressed in monetary or qualitative terms. If a project has a BCR greater than 1.0, the project is expected to deliver a positive net present value to a firm and its investors. Where, $\mathrm{BCR}=$ Benefit Cost Ratio and PV = Present Value, The benefit cost ratio is calculated by dividing the present value of benefits by that of costs and investments [41]. The present value of benefits is calculated as the sum of discounted benefits. To determine this sum, all inflows in a period (i.e. cash flows considered as benefits) need to be discounted with one plus the discount rate $i$ to the power of the period. This calculation needs to be performed for every period. The present value of costs is calculated analogously that of the benefits. The difference is that for this figure, the outflows are considered as representing costs, rather than the inflows. BCR is calculated by Equation (10).

$$
B C R=\frac{\mid P V[\text { Benefits }] \mid}{\mid P V[\text { cost }] \mid}
$$

\section{Internal rate of return (IRR)}

IRR is a well-known criterion in terms of projects' economic evaluation. This criterion specifies that greater IRR than the cost of capital is the project's acceptance

\begin{tabular}{|c|c|c|c|c|c|c|c|}
\hline \multirow{2}{*}{ Factor } & \multirow{2}{*}{ Variables } & \multirow{2}{*}{ Units } & \multicolumn{3}{|c|}{ Taguchi } & \multicolumn{2}{|c|}{ RSM } \\
\hline & & & Level 1 & Level 2 & Level 3 & Low Actual & High Actual \\
\hline A & Irradiance & $\mathrm{W} / \mathrm{m}^{2}$ & $200-500$ & $500-800$ & $800-1100$ & 200 & 1100 \\
\hline $\mathrm{B}$ & Temperature & ${ }^{\circ} \mathrm{C}$ & $20-30$ & $30-40$ & $40-50$ & 20 & 50 \\
\hline $\mathrm{C}$ & Wind Speed & $\mathrm{m} / \mathrm{s}$ & $0-1$ & $1-2$ & $2-3$ & 0 & 3 \\
\hline $\mathrm{D}$ & Flexibility & Degree & Flat & Cylinder & Sphere & 0 & $\pi$ \\
\hline
\end{tabular}
term. IRR stands for the discount rate based on which the NPV of the project is zero. If a project's NPV becomes positive, its IRR is greater than the return rate applied on

Table 2. Levels and responses of Taguchi and RSM design 
investment. In NPV calculation, it is assumed that the discount rate is apparent, while the NPV of the project ought to be determined. The deposit interest rate (sight deposit) in Iran has freshly reduced to $15 \%$. However, in the last 10 years, it has equated to $16.7 \%$, regarded as the benchmark discount rate. According to the Iranian parliament's legislation, each kilowatt of renewable electricity is purchased from the consumer at $\sim 0.05$ $\$ / \mathrm{kWh}$. This price is supposed to be 20 years of the solar system's useful lifetime [42]. Dehghan et al. [27] have considered the different feed-in tariff (FiT) rate to be 0.05 $\$ / \mathrm{kWh}$. In addition, the project's NPV is set to zero and the discount rate, which is the same as the project's IRR, is determined. The calculation of the IRR is based on the NPV which can be expressed as a function of the IRR. Equation (11) uses cash flows at regular intervals for the calculation of IRR.

$$
I R R=\frac{C F_{i}}{(1+r)^{i}}-C_{i n v}
$$

where $C F_{i}$ is cash flow in the time period, $r$ is discount rate, $i$ is time period and $C_{i n v}$ is initial investment. The IRR is the compounded discount rate for a given series of cash flows that leads to an NPV of 0 . IRR calculate by COMFAR through trial and error because you are trying to arrive at whatever rate which makes the NPV equal to zero.

\section{Payback period (PBP)}

Using the criterion of payback period, the period in which the sum of annual revenues is broken even with the investment cost is specified. The payback period involves normal and dynamic payback periods. In general, the product produced by this project is electricity, which flexible solar systems generate electricity at nominal production capacity. The PBP can be calculated using Equation (12) for each year [43].

$$
P B P=\frac{C_{i n v}}{C_{c f}}
$$

where $C_{i n v}$ is initial investment and $C_{c f}$ is net annual cash flow. Project fabrication duration, including the purchase and installation of equipment, has been intended for one year. The lifetime of the system is 20 years.

\section{RESULTS AND DISCUSSION}

JNPsolar3W-12V flexible solar arrays generate flexible solar energy systems by fitting them to flat, cylindrical, and hemispheric base surfaces. The implemented model tested such systems theoretically and economically. The short-circuit current and the open-circuit voltage are the maximum current and voltage respectively from a solar cell. However, at both of these operating points, the power from the solar cell is zero. The shape of I-V curve changes with the change in Fill Factor of solar cell which has been shown in Figure 2. By measuring the number of variances and its source of generation, the best output conditions were simultaneously predicted in systems, which is one of the advantages of using the Taguchi test method for solar energy systems. The minimum values of FF were calculated as 0.73 for the flat surface and 0.88 and 0.84 for the cylindrical and hemispherical surfaces, respectively. The more significant fill factor for systems supports the power controller to take more voltage and power distribution.

The relationship of temperature, radiation and flexibility variables at the optimum level is studied in the proposed model. When the radiation is at level one, the device will begin to operate. Irradiance ranges between $400 \mathrm{~W} / \mathrm{m}^{2}$ and $600 \mathrm{~W} / \mathrm{m}^{2}$; then, the effectiveness is a little diminished, but it is still optimal for the system and satisfies the objective. More than $1000 \mathrm{~W} / \mathrm{m}^{2}$ of irradiance will have a negative impact on system performance. With an overall view of the irradiance power and the SNR band, it can be shown that irradiance intensity may substantially affect the function of the electrical power generation capacity through distancing itself from the center line and high failure.

The temperature in the latter group and the temperature level (3) had the most significant impact on the performance of the solar energy device. Incoming wind speed from level (1) to level (2) was useful for the subsystem and could change the conditions to produce power at extremely high temperatures. Flexibility or angles of the photovoltaic solar panels has shown that the change in this element, including the usage of the system in flat style (level 1) or when installed on a spherical surface (level 2) or on a cylindrical surface (level 3), may affect the production of the full power objective. The system angle group and the SNR revealed that level (1) defined as the flat surface layer might significantly affect the solar system. The application of the system at level (2), i.e. the application of the system to the spherical surface, considering its proximity to the middle power

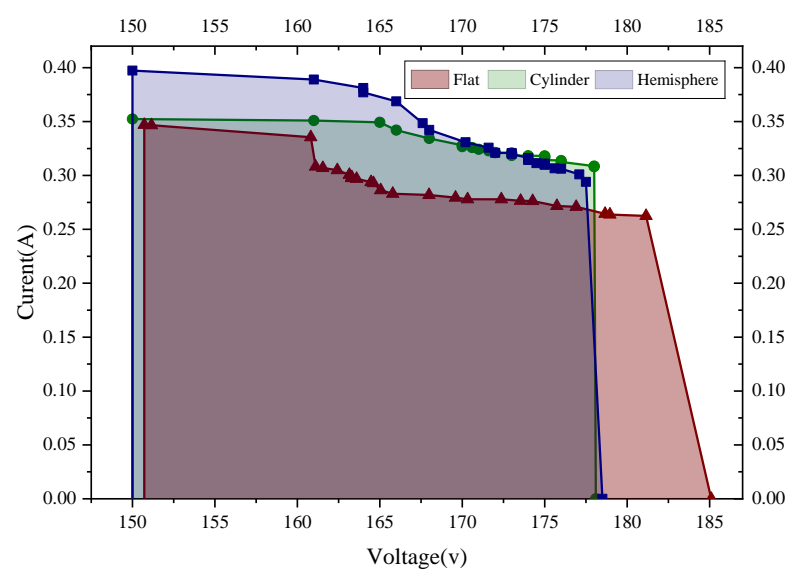

Figure 2. Current-voltage curve of systems 
line goal, is more efficient than the levels (1) and (3) Level (3) indicated that the application of the method to a cylindrical surface is more efficient than a flat surface, but the optimum output is at level (2). The use of the process on the roof in flat styles, such as bitumen, is therefore not taken priority. When a system needs both grain silos and biogas reservoirs in a farm simultaneously, the operation of the device under these conditions would be superior to the hemisphere level, which implies the biogas reservoir.

The largest effect on the function of the flexible photovoltaic system, is related to the rate of irradiance, wind speed, temperature, and use on various such as flat, cylindrical and spherical materials. In the present experiment, Taguchi's study found that if the device were evaluated at chosen levels based on the optimal manufacturing process and variables, it would be possible to predict a combined power of $49.9 \mathrm{~W}$ with $\mathrm{SNR}=$ 33.929. If the function is measured separately and on a fully flat surface strength of the function, it would be equal to $53.3 \mathrm{~W}$ with $\mathrm{SNR}=34.4918$. When the model was used to calculate the power on the cylindrical level, the device's power was equal to $54.05 \mathrm{~W}$ with $\mathrm{SNR}=$ 34.6368; for the hemispheric level, the corresponding power of $55.7 \mathrm{~W}$ with $\mathrm{SNR}=34.888$ was measured. The choice of the hemispheric surface is then classified into first and second-level cylinder points. According to the Taguchi experiments, the dynamic conditions applied to the flexible solar system indicate the ideal conditions for the use of a flexible panel-based solar conversion system. Priority will therefore be given to the use of a solar energy conversion solution based on flexible solar panels at various stages, as described below:

- These systems have good performance in the range of 500 to $800 \mathrm{~W} / \mathrm{m}^{2}$. If the ambient temperature is between 20 and $30{ }^{\circ} \mathrm{C}$, there will be no fall in performance due to the temperature on the cylindrical surface.

- For the next selection of the hemisphere's surface, it is best to have a consistent temperature, radiation, and wind speed parameters. The second level of radiation is $500-800 \mathrm{~W} / \mathrm{m}^{2}$ and the first level of temperature is $20-30{ }^{\circ} \mathrm{C}$ and the first level of wind is $0-1 \mathrm{~m} / \mathrm{s}$.

- The third choice for use of systems is for higher radiation up to more than $1000 \mathrm{~W} / \mathrm{m}^{2}$ in the middle of the day. This condition can occur in areas closer to the equator. The third level of radiation is $800-1100 \mathrm{~W} / \mathrm{m}^{2}$ and the first level of temperature is $20-30{ }^{\circ} \mathrm{C}$, whereas the third level of wind is $2-3 \mathrm{~m} / \mathrm{s}$ on the flat surface.

\section{Costs of BIPV in Iran}

After modeling the power of the systems using the variables A. Irradiance and B. Ambient Temperature, D. Surface Temperature C. Humidity E. Wind, the power equation of each system could be determined at any time of year by using weather conditions and irradiation. The systems' production capacity is calculated over the period of a year. Performance-based flexible systems at their maximum power production conditions can have other revenues when deployed on different surfaces. The flat surface system produced $810.369 \mathrm{kWh}$, the cylindrical surface $960.124 \mathrm{kWh}$, and the hemisphere surface $1000.165 \mathrm{kWh}$. Total Revenue Per Year can be calculated for each system if the feed-in tariff is set at $\$ 0.05$ Per $\mathrm{kWh}$. The cost (fixed price) of small-scale flexible photovoltaic panels is $0.8 \$ / \mathrm{W}$. Therefore, 56 Watts is equal to $\$ 44.8$ in 2020 . Thin-film technology has always been cheaper but less efficient than conventional c-Si technology. However, it has significantly improved over the years. Also, in addition to the panel, other equipment is also used in the flexible photovoltaic systems. The total cost of a flexible photovoltaic system including the purchase of panels, installation costs, etc. is estimated at \$ 181.78 according to the standard in current photovoltaic projects. Unforeseen costs included glue costs for reposing panels to surfaces, maintenance costs, and soil cleaning. The 20-year maintenance life of the solar system was estimated at $\$ 20$ per year. Sensitivity analysis is a calculation procedure that predicts the effects of changes on input data. Investment decisions are wracked with uncertainty and risk. Most investment models have explicit and implicit assumptions about the behaviors of models and the reliability and consistency of input data. If the changes made to the variables do not eliminate the project's justifiability, the investment will be much more favorable. In order to take into account factors not considered or the risk of agents endangering the return of the project, the sensitivity level of the project's indicators to these factors was estimated roughly. As shown in Figure 3, the irradiance peak is reached $1067.1 \mathrm{~W} / \mathrm{m}^{2}$.

In the cylinder, one side of the shadow and one side of the irradiance are usually present. For at least 3 hours, the irradiance will be greater than $735 \mathrm{~W} / \mathrm{m}^{2}$. It is likewise at its peak in the middle of the day. At sunset, the irradiance will be at its lowest and will finally hit zero. After sunrise, the irradiance power on the south side of the test cylinder increased with a gentle slope, reaching a

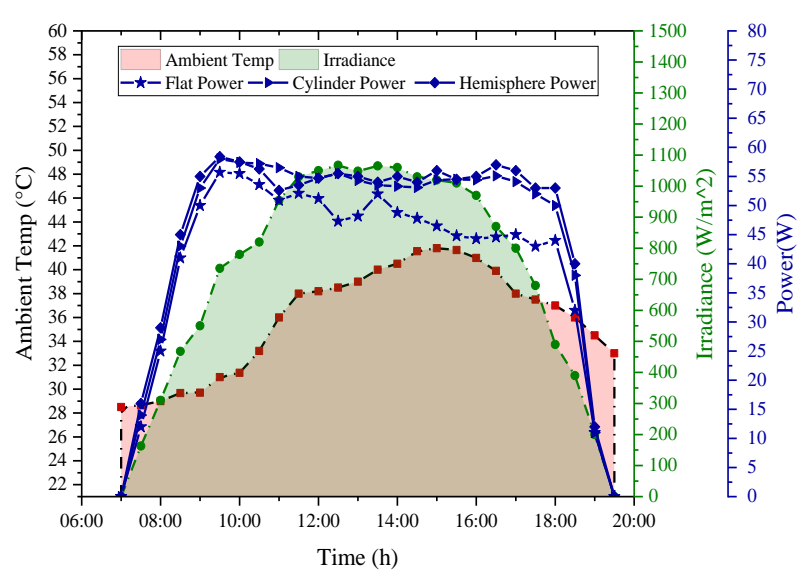

Figure 3. Power of systems against irradiance and ambient temperature 
maximum of $1048 \mathrm{~W} / \mathrm{m}^{2}$ in the afternoon (around 14:00). These adjustments regulated the form of curved surfaces like the Sin Type. Power in the hemisphere increased after sunrise and reached a maximum of $58.4 \mathrm{~W}$ at the beginning of the day. At midday (from 09:30 to 17:30), the power potential was almost constant at the hemispherical and cylindrical surface and was within the standard line range $(55.5 \mathrm{~W})$. Then, as the shade increases and the intensity of the light falls, the power decreases to zero.

The maximum power (MP) in Taguchi Method Test is related to the system deployment on the cylinder facade and is equal to $59.87 \mathrm{~W}$, while the minimum power of $57.84 \mathrm{~W}$ is related to the system when deployed on the flat surface, and maximum power in RSM Test is relevant to the system deployment on the hemispherical $(\mathrm{H})$ surface and equal to $61.14 \mathrm{~W}$ and minimum power of system is $56.6 \mathrm{~W}$ when related to the extent on the flat surface. The system's performance (SP) under standard test conditions (STC) $\left(25^{\circ} \mathrm{C}\right.$ and irradiance power of 1000 watts per $\mathrm{m}^{2}$ ) and in the laboratory for deploying on the cylinder and hemispherical facades has been measured $7.45 \%$. The winter solstice occurs during the hemisphere's winter. In the Northern Hemisphere, this is the December solstice (usually December 21 or 22) and in the Southern Hemisphere, this is the June solstice (usually June 20 or 21). The minimum performance was measured at $7.1 \%$ and related to the flat surface. In the model analysis, the open-circuit voltage at the flat system level was equal to 185.7 volts and the short-circuit current reached 0.347 in the most optimum scenario. Furthermore, the maximum production current was 0.36 amps when the system was deployed on the hemispherical surface. Therefore, the system in the case of deployment on the hemispherical surface by receiving diffusion irradiances and vertical irradiances has optimal electrical and quality characteristics compared to other deployment surfaces. The second and third priorities are related to the cylindrical and flat surfaces, respectively.

This study has shown that using an experimental design of Taguchi and RSM can explain the big data of solar energy systems. When the actual test data in these models will verify the correct orientation of the model. The irradiance and wind speed factors have a positive effect on the system power, whereas the temperature factor has a negative impact. the optimum power in the cylindrical surface is 60.27 Watts, once the ambient temperature is about $36^{\circ} \mathrm{C}$ and radiation is $1050 \mathrm{~W} / \mathrm{m}^{2}$, and the wind speed is zero, and the humidity is equal to $48.1 \%$. Figure 4 shows the sensitivity analysis of systems.

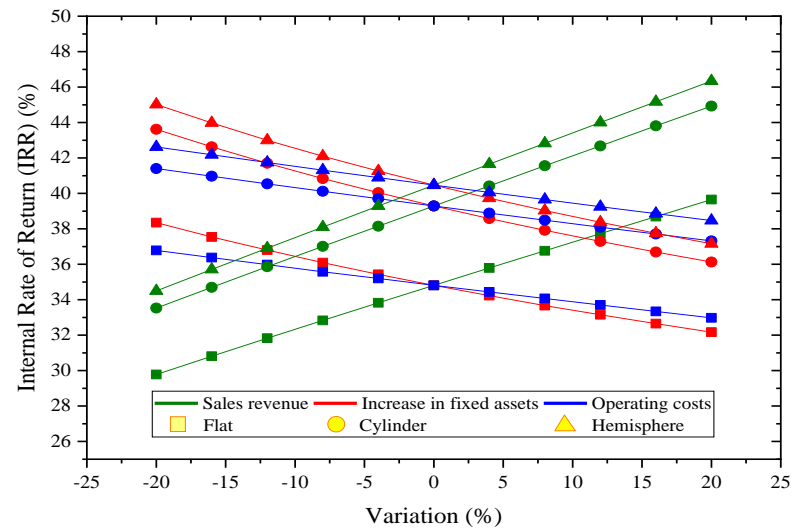

Figure 4. Effect of test variables on system power production quality in the actual test

The sensitivity analysis figure showed the impact of changing economic parameters by a variation percentage (decrease or increase) on the Internal Rate of Return (IRR). In all three systems, solar energy sales revenue has the greatest impact on investment attractiveness and IRR. This factor has a nearly equal slope. The investment attractiveness and IRR share of the flexible photovoltaic system are related to its use on flat, cylindrical, and hemisphere surfaces, respectively. The increase in fixed assets of systems is the next factor that investors consider. Because of the long life of a flexible photovoltaic system and the low cost of maintenance and other costs, the operating cost factor plays a minor role in these systems' investment decisions. The economic findings show that the NPV of the flexible solar energy system at $16.70 \%$, when applied at level 1, is \$ 697.52 and that the IRR is $34.81 \%$ and the capital return duration is 8.58 years. This amount is increased to $\$ 900.88$ in cylindrical surfaces and $\$ 955.18$ in hemispheres. The rate of return on investment was $39.29 \%$ at the cylindrical level and $40.47 \%$ at the hemisphere. In the flat-surface production method, a $20 \%$ rise in project budget raised the internal yield by $21.3 \%$ and a $20 \%$ fall in sales. The project's internal rate of return would be reduced by $23 \%$. Flexible solar systems installed on cylindrical and hemispheric surfaces with a $20 \%$ rise in project prices, with the IRR rising by $25.59 \%$ and $24.48 \%$, respectively. During the production time and deployment of flexible solar systems, the net flows were negative and when installed on cylindrical and hemispheric surfaces, from 7.2 years and 6.9 years to the end of the design period, the total net product flows were positive and constantly expanding. The description of the results is listed in Table 3.

Table 3. Systems behavioral assessment for more targets

\begin{tabular}{lcccccccc}
\hline Power Plant & MP Taguchi $(\mathbf{W})$ & MP RSM $(\mathbf{W})$ & FF $(\%)$ & S.P $(\%)$ & OCV $(\mathbf{V})$ & SCC $(\mathbf{A})$ & IRR & NPV \\
\hline Flat S. & 57.84 & 56.6 & 73 & 7.1 & 185 & 0.34 & 34.8 & 697.5 \\
Cylindrical S. & 59.87 & 57.71 & 88 & 7.4 & 179 & 0.35 & 39.2 & 900.8 \\
Hemisphere S. & 58.27 & 61.14 & 84 & 7.4 & 178 & 0.36 & 40.4 & 955.1 \\
\hline
\end{tabular}




\section{CONCLUSION}

We employed the actual capability of flexible solar energy conversion in this study, which was conducted utilizing environmental evaluation and environmental techniques centered on pilot projects. Annual energy production on the flat surface was $810 \mathrm{kWh}$, cylindrical surface $960 \mathrm{kWh}$, and hemisphere surface $1000 \mathrm{kWh}$. This shows that the findings were valid concerning RSM analysis. The system output current was limited to 0.36 amps when deployed on the hemispherical surface. Using Taguchi methods, research revealed that the influence of power production factors was surface temperature, irradiation, ambient temperature, wind, and humidity. The economic results indicate that NPV at Flat surface is $\$ 697.52$, with an IRR of $34.81 \%$ and a capital return term of 8.58 years. Cylindrical surfaces and hemispheres each see an increase of $\$ 955.18$. The investment yield returned $39.29 \%$ for cylindrical structures and $40.47 \%$ for spherical structures. Consequently, the order of economy in the systems would also be connected to a compact solar system installed on hemispheric, cylindrical and flat surfaces. The following can be stated as a general conclusion. In order to minimize the temperature decrease, the device must be mounted in place of the wind blinds. Radiation and temperature levels are higher than normal. A sensitivity analysis was performed to verify the economic analysis. It is proposed that modular systems be used in flags, towers, conventional structures, biogas tanks, grain storage silos, etc. It is preferable to install electrical systems on one side of the building, which is the largest average of shade. It is recommended that compact structures be used in regions similar to the equator and desert zones.

\section{REFERENCES}

1. Liobikienè, G., and Butkus, M., 2021. Determinants of greenhouse gas emissions: A new multiplicative approach analysing the impact of energy efficiency, renewable energy, and sector mix. Journal of Cleaner Production, 309, pp.127233. Doi: 10.1016/J.JCLEPRO.2021.127233

2. Jäger-Waldau, A., 2021. Overview of the Global PV Industry. Ref Modul Earth Syst Environ Sci. doi: 10.1016/B978-0-12-8197271.00054-6

3. IEA, Global Energy Review, 2021 - Analysis - IEA https://www.iea.org/reports/global-energy-review-2021 (accessed August 27, 2021)

4. Hasanien, H.M., 2018. Performance improvement of photovoltaic power systems using an optimal control strategy based on whale optimization algorithm. Electric Power Systems Research, 157, pp.168-176. Doi: 10.1016/j.epsr.2017.12.019

5. Yazid, M.N.A.W.M., Sidik, N.A.C., Mamat, R., and Najafi, G., 2016. A review of the impact of preparation on stability of carbon nanotube nanofluids. International Communications in Heat and Mass Transfer, 78, pp.253-263. Doi: 10.1016/J.ICHEATMASSTRANSFER.2016.09.021

6. Hong, Y.Y., Beltran, A.A., and Paglinawan, A.C., 2018. A robust design of maximum power point tracking using Taguchi method for stand-alone PV system. Applied Energy, 211(July 2017), pp.50-63. Doi: 10.1016/j.apenergy.2017.11.041

7. O'Shaughnessy, E., Cruce, J., and Xu, K., 2021. Rethinking solar PV contracts in a world of increasing curtailment risk. Energy Economics, 98, pp.105264. Doi: 10.1016/J.ENECO.2021.105264

8. Ettefaghi, E., Ghobadian, B., Rashidi, A., Najafi, G., Khoshtaghaza, M.H., Rashtchi, M., and Sadeghian, S., 2018. A novel bio-nano emulsion fuel based on biodegradable nanoparticles to improve diesel engines performance and reduce exhaust emissions. Renewable Energy, 125, pp.64-72. Doi: 10.1016/j.renene.2018.01.086

9. Najafi, G., and Ghobadian, B., 2011. LLK1694-wind energy resources and development in Iran. Renewable and Sustainable Energy Reviews, 15(6), pp.2719-2728. Doi: 10.1016/J.RSER.2011.03.002

10. Awad, O.I., Ali, O.M., Mamat, R., Abdullah, A.A., Najafi, G., Kamarulzaman, M.K., Yusri, I.M., and Noor, M.M., 2017. Using fusel oil as a blend in gasoline to improve SI engine efficiencies: A comprehensive review. Renewable and Sustainable Energy Reviews, 69, pp.1232-1242. Doi: 10.1016/J.RSER.2016.11.244

11. Chan, A.L.S., 2019. Effect of adjacent shading on the energy and environmental performance of photovoltaic glazing system in building application. Energy, 187, pp.115939. Doi: 10.1016/J.ENERGY.2019.115939

12. Oduyemi, O., and Okoroh, M., 2016. Building performance modelling for sustainable building design. International Journal of Sustainable Built Environment, 5(2), pp.461-469. Doi: 10.1016/j.ijsbe.2016.05.004

13. Zeb, R., Salar, L., Awan, U., Zaman, K., and Shahbaz, M., 2014. Causal links between renewable energy, environmental degradation and economic growth in selected SAARC countries: Progress towards green economy. Renewable Energy, 71, pp.123132. Doi: 10.1016/J.RENENE.2014.05.012

14. Azadbakht, M., Esmaeilzadeh, E., and Esmaeili-Shayan, M., 2015. Energy consumption during impact cutting of canola stalk as a function of moisture content and cutting height. Journal of the Saudi Society of Agricultural Sciences, 14(2), pp.147-152. Doi: 10.1016/j.jssas.2013.10.002

15. Shukla, A.K., Sudhakar, K., Baredar, P., and Mamat, R., 2018. BIPV based sustainable building in South Asian countries. Solar Energy, 170, pp.1162-1170. Doi: 10.1016/j.solener.2018.06.026

16. Rabab Mudakkar, S., Zaman, K., Shakir, H., Arif, M., Naseem, I., and Naz, L., 2013. Determinants of energy consumption function in SAARC countries: Balancing the odds. Renewable and Sustainable Energy Reviews, 28, pp.566-574. Doi: 10.1016/J.RSER.2013.08.006

17. Edalati, S., Ameri, M., Iranmanesh, M., Tarmahi, H., and Gholampour, M., 2016. Technical and economic assessments of grid-connected photovoltaic power plants: Iran case study. Energy, 114, pp.923-934. Doi: 10.1016/j.energy.2016.08.041

18. Al-Falahi, M.D.A., Jayasinghe, S.D.G., and Enshaei, H., 2019. Hybrid algorithm for optimal operation of hybrid energy systems in electric ferries. Energy, 187, pp.115923. Doi: 10.1016/J.ENERGY.2019.115923

19. Zohoori, M., 2012. Exploiting Renewable Energy Sources in Iran. Interdisciplinary Journal of Contemporary Research in Business, 4(7), pp.849-862.

20. Solangi, K.H., Islam, M.R., Saidur, R., Rahim, N.A., and Fayaz, H., 2011. A review on global solar energy policy, Renewable and sustainable energy reviews, 15(4), pp.2149-2163. Doi: 10.1016/j.rser.2011.01.007

21. Salehi-Isfahani, D., and Mostafavi-Dehzooei, M.H., 2018. Cash transfers and labor supply: Evidence from a large-scale program in Iran. Journal of Development Economics, 135, pp.349-367. Doi: 10.1016/J.JDEVECO.2018.08.005 
22. Esmaeili Shayan, M., 2020. Solar Energy and Its Purpose in NetZero Energy Building. In: Pérez-Fargallo A, Oropeza-Perez I (eds) Zero-energy Buildings. New approaches and technologies. IntechOpen.

23. Esmaeili shayan, M., Najafi, G., and Gorjian, S., 2020. Design Principles and Applications of Solar Power Systems, First Edit ACECR Publication- Amirkabir University of Technology Branch, Tehran. (In Persian)

24. Barr, M.C., Rowehl, J.A., Lunt, R.R., Xu, J., Wang, A., Boyce, C.M., Im, S.G., Bulović, V., and Gleason, K.K., 2011. Direct Monolithic Integration of Organic Photovoltaic Circuits on Unmodified Paper. Advanced Materials, 23(31), pp.3500-3505. Doi: 10.1002/adma.201101263

25. Chen, J., E, J., Kang, S., Zhao, X., Zhu, H., Deng, Y., Peng, Q., and Zhang, Z., 2019. Modeling and characterization of the mass transfer and thermal mechanics of the power lithium manganate battery under charging process. Energy, 187, pp.115924. Doi: 10.1016/J.ENERGY.2019.115924

26. Padmanathan, K., Govindarajan, U., Ramachandaramurthy, V.K and Jeevarathinam, B., 2018. Integrating solar photovoltaic energy conversion systems into industrial and commercial electrical energy utilization-A survey. Journal of Industrial Information Integration, 10, pp.39-54. doi: 10.1016/j.jii.2018.01.003

27. Dehghan, M., Rahgozar, S., Pourrajabian, A., Aminy, M., and Halek, F.S., 2021. Techno-economic perspectives of the temperature management of photovoltaic (PV) power plants: A case-study in Iran. Sustainable Energy Technologies and Assessments, 45, pp.101133. Doi: 10.1016/j.seta.2021.101133

28. Keshtegar, B., Mert, C., and Kisi, O., 2018. Comparison of four heuristic regression techniques in solar radiation modeling: Kriging method vs RSM, MARS and M5 model tree. Renewable and Sustainable Energy Reviews, 81(July 2017), pp.330-341. Doi: 10.1016/j.rser.2017.07.054

29. Ghritlahre, H.K., and Prasad, R.K., 2018. Application of ANN technique to predict the performance of solar collector systems A review. Renewable and Sustainable Energy Reviews, 84(December 2017), pp.75-88. Doi: 10.1016/j.rser.2018.01.001

30. Esmaeili Shayan, M., and Ghasemzadeh, F., 2020. Nuclear Power Plant or Solar Power Plant. In: Awwad N (ed) Nuclear Power Plants - The Processes from the Cradle to the Grave. IntechOpen, Landon.

31. Najafi, G., Ghobadian, B., Yusaf, T., and Rahimi, H., 2007. Combustion analysis of a CI engine performance using waste cooking biodiesel fuel with an artificial neural network aid. American Journal of Applied Sciences, 4(10), pp.756-764. http://eprints.usq.edu.au/id/eprint/2483

32. Mat Yasin, M.H., Mamat, R., Najafi, G., Ali, O.M., Yusop, A.F., and Ali, M.H., 2017. Potentials of palm oil as new feedstock oil for a global alternative fuel: A review. Renewable and Sustainable Energy Reviews, 79, pp.1034-1049. Doi: 10.1016/J.RSER.2017.05.186
33. Yin, Y., Liu, T., and He, C., 2019. Day-ahead stochastic coordinated scheduling for thermal-hydro-wind-photovoltaic systems. Energy, 187, pp.115944. Doi: 10.1016/J.ENERGY.2019.115944

34. Mohammadi, M., Ghasempour, R., Razi Astaraei, F., Ahmadi, E., Aligholian, A., and Toopshekan, A., 2018. Optimal planning of renewable energy resource for a residential house considering economic and reliability criteria. International Journal of Electrical Power \& Energy Systems, 96, pp.261-273. Doi: 10.1016/J.IJEPES.2017.10.017

35. Bloem, J.J.J., Lodi, C., Cipriano, J., and Chemisana, D., 2012. An outdoor Test Reference Environment for double skin applications of Building Integrated PhotoVoltaic Systems. Energy and Buildings, 50, pp.63-73. Doi: 10.1016/j.enbuild.2012.03.023

36. JMP. JNP. Jmpsolarpower 2017. https://jmpsolarpower.com/ (accessed February 15, 2018).

37. Yan, J., Luo, G., Xiao, B., Wu, H., He, Z., and Cao, Y., 2015. Origin of high fill factor in polymer solar cells from semiconducting polymer with moderate charge carrier mobility. Organic Electronics, 24, pp.125-130. Doi: 10.1016/J.ORGEL.2015.05.034

38. Abdolbaqi, M.K., Azmi, W.H., Mamat, R., Mohamed, N.M.Z.N., and Najafi, G., 2016. Experimental investigation of turbulent heat transfer by counter and co-swirling flow in a flat tube fitted with twin twisted tapes. International Communications in Heat and Mass Transfer, C(75), pp.295-302. Doi: 10.1016/J.ICHEATMASSTRANSFER.2016.04.021

39. Graff, K.M., and Eng, B., 2014. Environmental Effects on the Operation of Triple-Junction Flexible Photovoltaic Panels, Doctoral dissertation, Carleton University, Ottawa. Doi: 10.22215/etd/2014-10332

40. Milkey, K.R., Samsudin, A.R., Dubey, A.K. and Kidd, P., 2014 Comparison between Taguchi Method and Response Surface Methodology (RSM) in Modelling $\mathrm{CO}_{2}$ Laser Machining. JJMIE Jordan Journal of Mechanical and Industrial Engineering, 8(1), pp. 35-42.

41. Schwab, B., and Lusztig, P., 1969. A Comparative Analysis of the Net Present Value and the Benefit-Cost Ratio as Measures of the Economic Desirability of Investments. The Journal of Finance, 24(3), pp. 507-516. Doi: 10.2307/2325349

42. Bozorgparvar, E., Yazdanpanah, M., Forouzani, M., and Khosravipour, B., 2018. Cleaner and greener livestock production: Appraising producers' perceptions regarding renewable energy in Iran. Journal of Cleaner Production, 203, pp.769-776. Doi: 10.1016/J.JCLEPRO.2018.08.280

43. Singh, D.B., Tiwari, G.N., Al-Helal, I.M., Dwivedi, V.K., and Yadav, J.K., 2016. Effect of energy matrices on life cycle cost analysis of passive solar stills. Solar Energy, 134, pp.9-22. Doi: 10.1016/J.SOLENER.2016.04.039

\section{COPYRIGHTS}

(C)2021 The author(s). This is an open access article distributed under the terms of the Creative Commons Attribution (CC BY 4.0), which permits unrestricted use, distribution, and reproduction in any medium, as long as the original authors and source are cited. No permission is required from the authors or the publishers. 


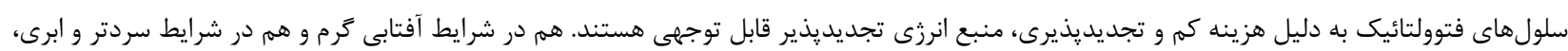

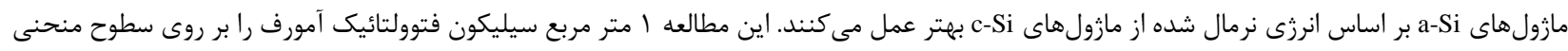

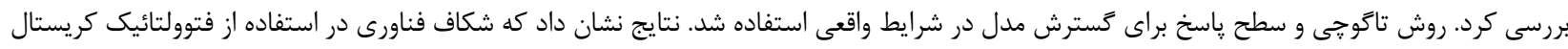

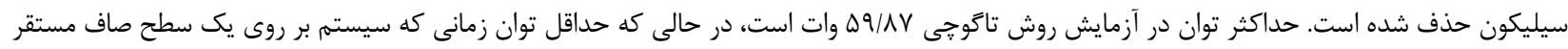

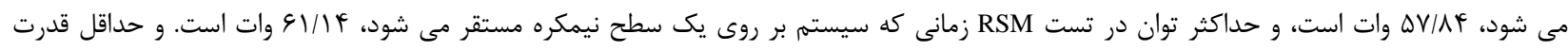
•

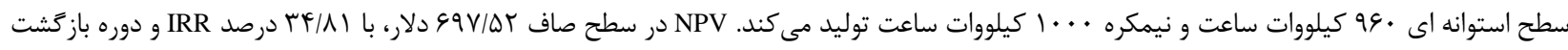

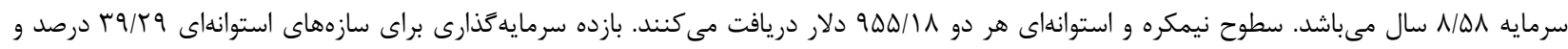

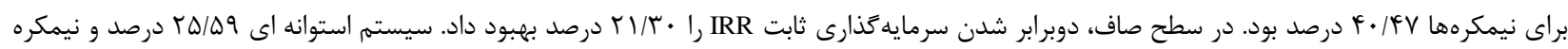

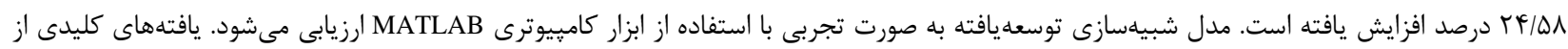

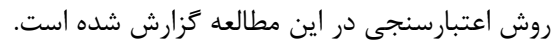

